\title{
Chapter 7 \\ Understanding of Processing, Microstructure and Property Correlations for Flat Rolling of Presintered TRIP-Matrix Composites
}

\author{
Sergey Guk, Rudolf Kawalla and Ulrich Prahl
}

\begin{abstract}
Descriptions of material behavior during forming operations have become increasingly important in recent years due to the increasing use of simulation systems for understanding processing-microstructure-property correlations and regulating forming facilities. This information has become particularly important for composite materials, including metal matrix composites. This necessity poses new challenges in particular for testing technology, which significantly contributes to the analysis of material characteristics. The characteristic values of materials are prerequisites for the numerical design of manufacturing processes. This chapter presents an overview of the strategies currently available for describing material behavior during flat rolling; the materials investigated herein are presintered TRIP-matrix composites. In addition, the test procedures and methods necessary for determining material parameters are briefly listed and explained. Furthermore, this chapter presents both the classical test methods and equipment and their areas of application, which have been further developed in recent years.
\end{abstract}

\subsection{Introduction}

For the development, industrial production, and processing of materials, it is becoming increasingly necessary to describe and optimize the associated technologies as completely as possible with the help of models. Depending on the manufacturing conditions, the corresponding models can then be used to estimate important characteristics of the surface (scale), geometry, microstructure, texture, internal stresses, mechanical properties, and physical properties of materials. For the customer, the mechanical properties of construction materials, which-depending on the field of application-may be combined with the chemical or special physical properties of the semifinished product or component, are often in the foreground [1].

\footnotetext{
S. Guk (凶) · R. Kawalla $\cdot$ U. Prahl

Institute for Metal Forming, Technische Universität Bergakademie Freiberg,

Bernhard-von-Cotta-Str. 4, 09599 Freiberg, Germany

e-mail: sergey.guk@imf.tu-freiberg.de 
The entirety of the material description often represents an almost insoluble task in its complexity. Rather, individual models are linked together on different bases and used depending on a particular specification as well as scientific and technical requirements [2].

From the process description perspective, material models for flow curves, formability and physical properties, such as thermal conductivity and heat capacity as a function of temperature, are required for the forming process, among other things $[3,4]$. Such models enable the material flow in the forming zone to be described and the characteristic values for the load and design of forming facilities to be calculated in advance. For multistage forming processes, some models must include time as an influencing factor, especially for all diffusion-controlled processes during deformation pauses. The resulting structural changes must be incorporated into the description via metallurgical models, which contributes to better calculation results.

The product properties of components are ultimately determined by the microstructure conditions, which can be specifically influenced during fabrication and further processing using various forming operations. The interaction of forming and microstructural development is illustrated in Table 7.1. A continuous description of the material behavior according to the column "Technologically related parameters" is possible with several methods if the necessary forming parameters and the physical properties are known. Microstructural development can be determined through the simplest methods of regression, semiempirical or semiphysical equations or complex computational methods on a physical basis.

The relationships between the forming conditions and the microstructural development during the production of cold and hot strips from transformation-induced plasticity (TRIP)-matrix composites, which are highlighted in italics in Table 7.1, are described below. The remaining microstructural developments, such as grain growth or precipitation of the $\delta$-ferrite phase, have either already been discussed in

Table 7.1 Interlocking interaction of forming and microstructural development in cold and hot forming processes

\begin{tabular}{l|l|l|l}
\hline Process & Technological step & $\begin{array}{l}\text { Technologically related } \\
\text { parameters }\end{array}$ & $\begin{array}{l}\text { Microstructural } \\
\text { development }\end{array}$ \\
\hline Cold forming & Forming & $\begin{array}{l}\text { Distribution of forming } \\
\text { parameters }\end{array}$ & $\begin{array}{l}\text { Strain hardening } \\
\text { Formability } \\
\text { Material flow/texture }\end{array}$ \\
\hline \multirow{2}{*}{ Hot forming } & Heating & $\begin{array}{l}\text { Heating curve } \\
\text { Temperature profile }\end{array}$ & $\begin{array}{l}\text { Grain growth } \\
\text { Dissolution of precipitates }\end{array}$ \\
\cline { 2 - 4 } & Forming & $\begin{array}{l}\text { Distribution of forming } \\
\text { parameters } \\
\text { Cooling curve } \\
\text { Temperature profile }\end{array}$ & $\begin{array}{l}\text { Strain hardening } \\
\text { Strain softening } \\
\text { Formability } \\
\text { Material flow/texture } \\
\text { Precipitation }\end{array}$ \\
\cline { 2 - 4 } & Cooling & $\begin{array}{l}\text { Cooling curve } \\
\text { Temperature profile }\end{array}$ & $\begin{array}{l}\text { Phase transformation } \\
\text { Precipitation }\end{array}$ \\
\hline
\end{tabular}


the Chap. 6 of this volume or are of minor relevance compared to the others in this context. The material used was a TRIP-matrix composite produced by the powder metallurgical route with different fractions of ceramic particles. In this chapter, the details of material data, sample preparation, and testing to characterize the material behavior during deformation under conditions similar to flat rolling at different temperatures are provided in Sect. 7.2. Section 7.3 presents the results of the experimental observations and corresponding discussions involving comparisons with the state of the art. Finally, the investigation is concluded in Sect. 7.4.

\subsection{Materials and Methods}

The investigated material is based on two components: a Mn-containing gas-atomized metastable high-alloyed TRIP-steel powder $\left(d_{10}=8 \mu \mathrm{m}, d_{50}=23 \mu \mathrm{m}, d_{90}=\right.$ $45 \mu \mathrm{m}$, and $\rho=7.81 \mathrm{~g} / \mathrm{cm}^{3}$ ). On the other hand, there is a powder of MgO partly stabilized $\mathrm{ZrO}_{2}$, which was separated by means of wind sifting into four fractions with corresponding particle size distributions:

1. $<10 \mu \mathrm{m}\left(d_{10}=0.7 \mu \mathrm{m}, d_{50}=2.5 \mu \mathrm{m}\right.$ and $\left.d_{90}=9.0 \mu \mathrm{m}\right)$;

2. $\quad 10-30 \mu \mathrm{m}\left(d_{10}=12.5 \mu \mathrm{m}, d_{50}=20.7 \mu \mathrm{m}\right.$ and $\left.d_{90}=29.1 \mu \mathrm{m}\right)$;

3. 30-50 $\mu \mathrm{m}\left(d_{10}=32.2 \mu \mathrm{m}, d_{50}=39.0 \mu \mathrm{m}\right.$ and $\left.d_{90}=48.6 \mu \mathrm{m}\right)$ and

4. $>50 \mu \mathrm{m}\left(d_{10}=52.4 \mu \mathrm{m}, d_{50}=56.8 \mu \mathrm{m}\right.$ and $\left.d_{90}=81.9 \mu \mathrm{m}\right)$.

The chemical composition of the steel and the ceramic powders are shown in Table 7.2. The proportions of the phases in $\mathrm{ZrO}_{2}$ were distributed between monoclinic (m), tetragonal (t) and cubic (c) crystallographic modifications at approximately equal amounts of 35:32:33\%. By varying the ceramic particle content between 0 and $30 \%$ during blending as well as varying the ceramic particle size distribution, different powder mixtures were obtained. These mixtures were cold precompressed into disc form with a diameter of $155 \mathrm{~mm}$ and a height of $36 \mathrm{~mm}$ at a uniaxial pressure of $90 \mathrm{MPa}$ and finally hot-press sintered. The sintering was carried out under a Varigon $\left(5 \% \mathrm{H}_{2}\right.$ and $95 \% \mathrm{Ar}$ ) atmosphere at $1250{ }^{\circ} \mathrm{C}$ and $30 \mathrm{MPa}$ for $30 \mathrm{~min}$. Metallographic examinations clearly showed that the particle distribution in the steel matrix was nearly homogenous. Only small agglomerates of ceramic particles were found for the composites with 20 and $30 \% \mathrm{ZrO}_{2}$ (Fig. 7.1). The porosity measurements using

Table 7.2 Chemical compositions of the investigated powders (wt $\%)$

\begin{tabular}{l|l|l|l|l|l|l|l|l|l|l|l}
\hline Steel powder \\
\hline $\mathrm{C}$ & $\mathrm{Cr}$ & $\mathrm{Mn}$ & $\mathrm{Ni}$ & $\mathrm{Si}$ & $\mathrm{N}$ & $\mathrm{S}$ & $\mathrm{Mo}$ & $\mathrm{Ti}$ & $\mathrm{Nb}$ & $\mathrm{Al}$ & $\delta$-Ferrite \\
\hline 0.03 & 16.4 & 6.3 & 6.3 & 0.9 & 0.06 & 0.008 & 0.02 & 0.003 & 0.021 & 0.10 & 16 \\
\hline $\mathrm{ZrO}_{2}$ powder & $\mathrm{ZrO}_{2}$ & $\mathrm{SiO}_{2}$ & $\mathrm{HfO}_{2}$ & $\mathrm{CaO}$ & $\mathrm{MgO}$ & $\mathrm{TiO}_{2}$ & $\mathrm{Fe}_{2} \mathrm{O}_{3}$ \\
\hline Bal. & 0.41 & 1.74 & 0.15 & 2.82 & 0.13 & 0.13 \\
\hline
\end{tabular}


(a)

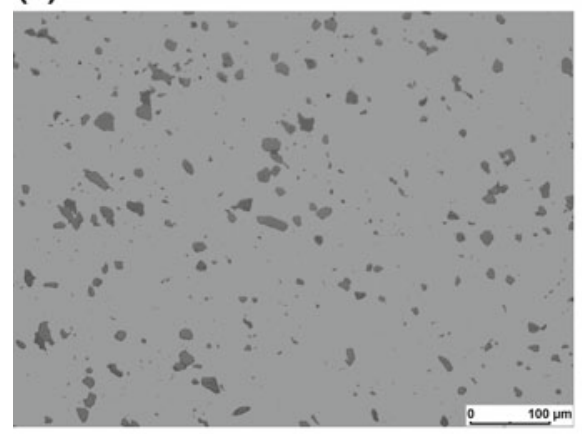

(c)

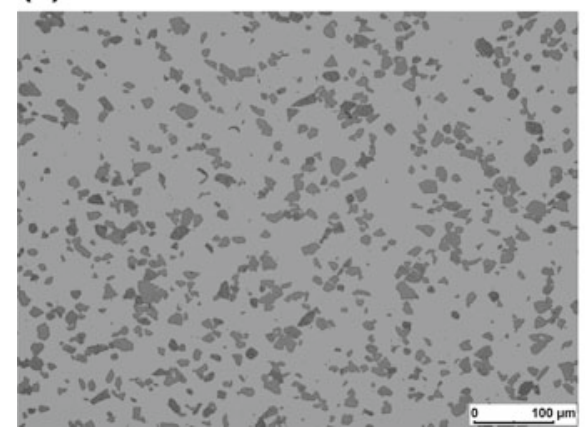

(b)

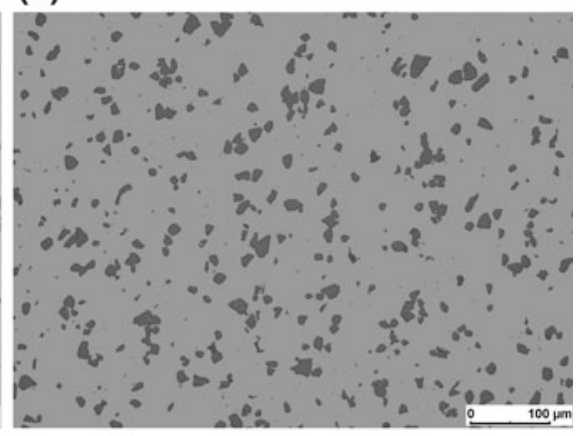

(d)

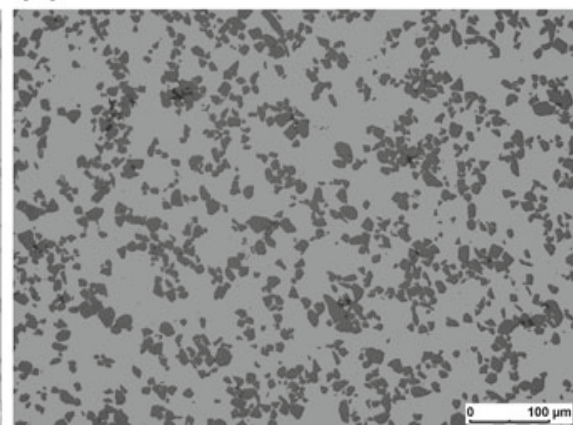

Fig. 7.1 Distribution of second-phase particles of $\mathrm{ZrO}_{2}$ with particle sizes between 10 and $30 \mu \mathrm{m}$ in the steel matrix: a $5 \%$, b $10 \%$, c $20 \%$, d $30 \% \mathrm{ZrO}_{2}[5,6]$

the Archimedes method, conducted in accordance with DIN EN 623-2:1993, showed that nearly full density was achieved: the values of total porosity were at most $0.1 \%$. The measured proportions of $\mathrm{m}-$, $\mathrm{t}-$ and $\mathrm{c}-\mathrm{ZrO}_{2}$ after hot pressing were $60: 7: 33 \%$.

The solution state of the steel matrix defined by the selected heating rates and temperatures was calculated for the investigated chemical composition using ChemSage, a computer program for calculating complex chemical equilibria, and SteelMap, a program specializing in calculations with steels. The calculation took place in a temperature interval between 200 and $1200{ }^{\circ} \mathrm{C}$ in $10 \mathrm{~K}$ steps. The calculated solution states are valid for the thermodynamic equilibrium and reflect the possible maximum values related to the experimental test conditions.

A completely new approach was chosen to determine the nonrecrystallization temperature. Usually, an attempt is made to determine the region of nonrecrystallization using a torsion machine [7, 8]. The machined samples are subjected to torsional stress and then evaluated. However, a decisive disadvantage lies in the sample geometry because the stress is not distributed homogeneously over the cross-section of the sample. Therefore, a MAXStrain ${ }^{\circledR}$ device in the multifunctional simulation system GLEEBLE HDS-V40 (Dynamic Systems Inc.) was applied to determine the nonrecrystallization temperature (Fig. 7.2). Due to the cube-shaped geometry of the 
Fig. 7.2 Determination of the nonrecrystallization temperature using the MAXStrain ${ }^{\circledR}$ device

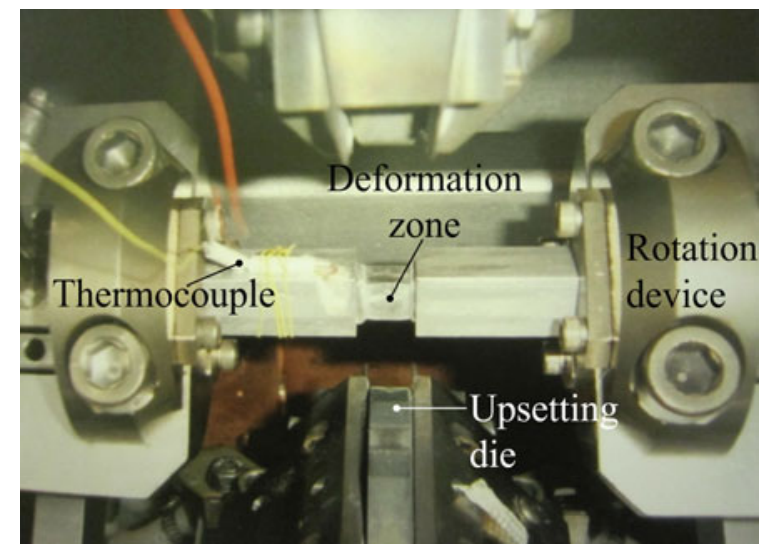

deformation zone in the MAXStrain ${ }^{\circledR}$ specimens, this influence is eliminated. An alternating deformation of the cube-shaped zone of the specimen with a strain value of 0.5 per deformation step is carried out by means of upsetting dies and a $90^{\circ}$ rotation of the specimen after each deformation step. Twenty deformation steps were performed with a strain rate of $10 \mathrm{~s}^{-1}$ and a pause time of $8 \mathrm{~s}$. Then, by recording the stress development during the reduction in deformation temperature from 1100 to $700{ }^{\circ} \mathrm{C}$ at $20 \mathrm{~K}$ decrements per deformation step, the region of nonrecrystallization due to strongly increasing stress levels can be determined.

To determine the strain hardening behavior of consolidated samples, compression tests were carried out at room temperature and in the range between 700 and $1200{ }^{\circ} \mathrm{C}$ with a $100 \mathrm{~K}$ step using the servo-hydraulic test system with a maximum force of $400 \mathrm{kN}$. The upsetting samples to be tested were taken from the hot-pressed discs in the axial direction. The specimen dimensions for the cylindrical compression tests were $\varnothing 10 \mathrm{~mm} \times 18 \mathrm{~mm}$. The test was carried out in accordance with DIN 50106:2016. The strain rates were $0.1,1$ and $10 \mathrm{~s}^{-1}$. To reduce friction, the end faces of the cylindrical specimens were lubricated with oil (for tests under room temperature) or graphite solution (for tests under high temperatures). Flow curves were calculated based on the data obtained with friction and temperature adjustments [9]. These adjustments were based on the physical and tribological properties, such as density, heat capacity and friction coefficient, which were determined experimentally for all investigated composite material states.

To evaluate the kinetics of the $\alpha^{\prime}$-martensite evolution for the steel matrix under room temperature testing conditions, the ferromagnetic phase fraction of the samples with different contents of $\mathrm{ZrO}_{2}$ particles were measured using magnetic balance testing (Metis Instruments and Equipment NV) and a previous calibration. The measuring principle is based on a magnetic induction method. In the investigated steel matrix, ferromagnetic phases, such as $\delta$-ferrite and $\alpha^{\prime}$-martensite, can be found. At the beginning of each experiment (i.e., in the $\alpha^{\prime}$-martensite-free state), the amount of $\delta$-ferrite was determined to extract these contents from the measurement values of the experiment, thereby determining the exact amount of $\alpha^{\prime}$-martensite. 
The determination of the softening kinetics was carried out on the multifunctional simulation system GLEEBLE HDS-V40 by means of a cylinder compression test (dynamic softening) and a double compression test (static softening). In the double compression test, a specimen was deformed at a constant strain rate of $1 \mathrm{~s}^{-1}$ up to a strain of 0.4 , unloaded and, after a variable isothermal holding time, was loaded again at the original strain rate up to the strain value above. Here, cylindrical samples with dimensions of $\varnothing 10 \times 18 \mathrm{~mm}$, which were taken from the hot-pressed disc axis direction, were heated to the deformation temperature at a heating rate of $3 \mathrm{~K} / \mathrm{s}$ and held at this temperature for $1 \mathrm{~min}$. The double compression tests were carried out at temperatures between 900 and $1100{ }^{\circ} \mathrm{C}$. To minimize the influence of friction and heat of deformation on the flow stress and subsequently on the hardening and softening characteristics, all measured flow curves were subjected to a temperature and friction adjustment [9]. The flow curves were evaluated according to the offset method [10]. The modeling of the dynamic softening behavior was carried out with the help of reaction kinetic calculation equations [10-13] based on data from the experimentally generated flow curves. For strains over the critical value, dynamic recrystallization can take place. Otherwise, only dynamic recovery occurs. The part of the dynamic recovery is described by

$$
\sigma_{\mathrm{DRV}}(\varepsilon)=u \cdot \sqrt[n_{2}]{1-\exp \left(-r \cdot \varepsilon^{n_{1}}\right)}
$$

The dynamic recrystallization degree is described by

$$
\sigma_{\mathrm{DRX}}(\varepsilon)=a \cdot \dot{\varepsilon}^{c} \cdot \exp \left(\frac{\Theta_{2}}{R \cdot \Theta}\right) .
$$

The static recrystallization degree is described by

$$
X_{\text {stat }}=1-\exp \left(h_{1} \cdot\left[\frac{t}{t_{0.5}}\right]^{h_{2}}\right) \text {. }
$$

To determine the cold formability of the composite materials under deformation conditions similar to flat rolling, transverse extrusion tests were carried out on the servo-hydraulic press with a maximum force of $400 \mathrm{kN}$ at room temperature (Fig. 7.3a); these tests were repeated six times for each sample type. A simplified illustration of the transverse extrusion tool used is shown in Fig. 7.3b. Cylindrical specimens with dimensions of $\varnothing 10.65 \mathrm{~mm} \times 19 \mathrm{~mm}$ were machined from the hotpressed discs. Before inserting a specimen into the test tool, it was lubricated on all sides with hydraulic oil. The strain rate in all tests was $0.1 \mathrm{~s}^{-1}$. The evaluation of the tests was carried out according to the methodology described in $[14,15]$.

The hot formability was characterized according to the methodology of [16] based on the hot flow curves measured under different temperatures and strain rates. The energy dissipation and an instability map were generated based on these experimental 

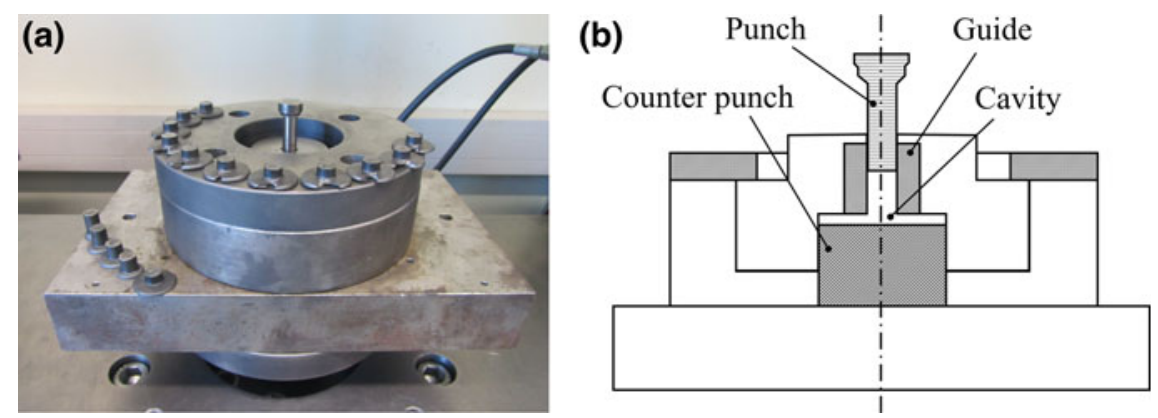

Fig. 7.3 Transverse extrusion tool: a photograph and $\mathbf{b}$ schematic drawing

results, and a process map was derived. The numerical analysis was carried out by means of a MATLAB ${ }^{\circledR}$ subroutine.

The hot rolling tests were carried out on a reversible stand with a dual roll mill, which has a maximum rolling force of $2.4 \mathrm{MN}$ and a maximum rolling torque of $60 \mathrm{kN} \mathrm{m}$. The rolls used had a diameter of $360 \mathrm{~mm}$. The rolls were preheated to approximately $150{ }^{\circ} \mathrm{C}$. The roll speed was chosen to be constant at $0.5 \mathrm{~m} / \mathrm{s}$. The samples were preheated in a furnace and purged with inert argon gas to prevent scale formation on the metallic surface. After rolling, the samples were cooled to room temperature in air.

Sheets, stuck rolling specimens and wedge rolling specimens were flat rolled. Stuck rolling specimens were only partially rolled products that_after removing the specimen from the roll gap_-produce a largely realistic image of the deformation conditions directly in the roll gap. This technique made it possible to carry out extensive and complex investigations on the influence of the roll gap geometry on the extension and overall spread of material, the rolling force and torque, and the mean deformation resistance during hot rolling. Moreover, this technique helped clarify the material flow along the length of the contact arc as a function of the roll gap geometry. In contrast, the wedge rolling specimens represented initial semifinished products with a wedge-shaped longitudinal cross-section of $135 \times 20 \mathrm{~mm}^{2}$, which consequently undergo different strains over the specimen length during rolling with a constant roll gap. Thus, the evaluation of the rolling parameters, such as pass reduction, deformation temperature and strain rate, could be carried out with fewer initial samples. For mesoscopic characterization of the material flow, the initial specimens were marked with grid patterns (line spacing of $5.0 \mathrm{~mm}$ and a depth of approximately $0.3 \mathrm{~mm}$ ) for forming strain analysis by means of the laser marking system Lasebox XS (Östling Marking Systems GmbH) on the surface and cross-sectional area $[17,18]$. On the microscopic scale, densification processes and material flow were analyzed using light microscopy and scanning electron microscopy (SEM) on transverse and longitudinal sections from the different areas of the deformation zone. For this aim, the samples were cut, ground and polished. The degree of orientation of partially oriented linear structure elements $A I$ and $\Omega_{12}$, which characterize the 
banding of the material, was measured in accordance with ASTM E 1268:94. These degrees of orientation were calculated with the following equations:

$$
\begin{gathered}
A I=\frac{\overline{N_{L \perp}}}{\overline{N_{L \|}}} \\
\Omega_{12}=\frac{\overline{N_{L \perp}}-\overline{N_{L \|}}}{\overline{N_{L \perp}}+0.571 \cdot \overline{N_{L \|}}},
\end{gathered}
$$

where $\overline{N_{L \perp}}$ and $\overline{N_{L \|}}$ are the numbers of feature interceptions with test lines perpendicular to the deformation direction and in parallel direction, respectively. The degree of orientation $\Omega_{12}$ can vary from zero for a completely random distribution to one for a fully oriented material (banding microstructure).

\subsection{Results}

\subsubsection{Heating and Dissolution of Precipitates}

The investigations on the dissolution behavior of precipitates during heating of the steel matrix aimed to determine in advance the possible causes for influencing recrystallization and determine an optimum heating temperature for the composite material before forming from the perspective of the completely dissolved alloying elements. After heating to $900{ }^{\circ} \mathrm{C}$ and holding for $3 \mathrm{~min}$, undissolved precipitates were determined in the steel matrix using the energy-dispersive X-ray spectroscopy (EDX) method; these precipitates essentially consisted of chromium (Fig. 7.4a). The precipitates have a size range from 70 to $300 \mathrm{~nm}$ [19].

Figure $7.4 \mathrm{~b}$ shows the precipitation fraction as a function of the heating temperature. According to this figure, chromium carbonitrides are precipitated at $900{ }^{\circ} \mathrm{C}$ after
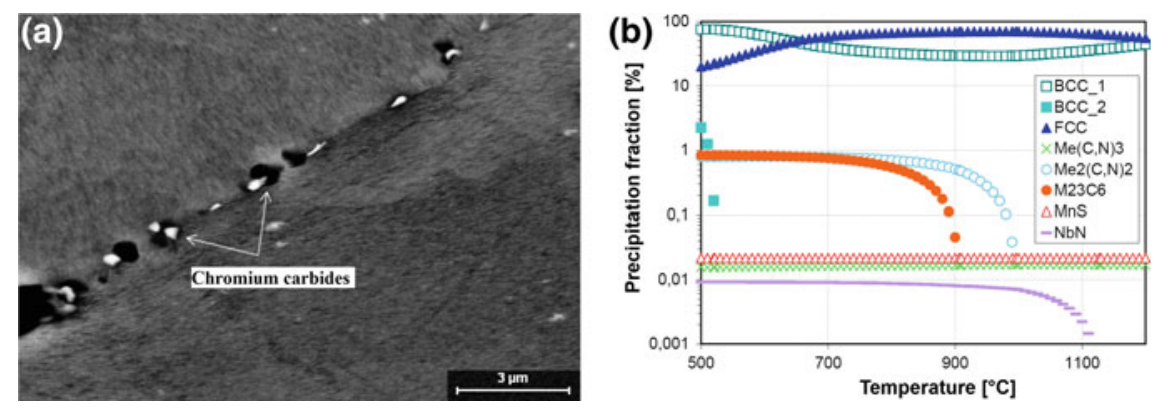

Fig. 7.4 a SEM image of the steel matrix with $\mathrm{Cr}$ carbides precipitated at the grain boundaries and b the calculated dissolution behavior of the precipitates of the investigated steel matrix 
heating close to equilibrium; this finding has also been validated. The identification of the precipitates was carried out by means of EDX analysis. This analysis showed a high chromium content of $28 \%$. The figure also shows that $\mathrm{NbN}$ precipitates in steel are resistant up to a temperature of $1120{ }^{\circ} \mathrm{C}$ and only then dissolve. For this reason, it was decided to set the heating temperature to $1100^{\circ} \mathrm{C}$ to obtain a homogeneous matrix with dissolved chromium carbonitrides, inhibit normal grain growth, and prevent abnormal grain growth at the cost of retaining $\mathrm{NbN}$ precipitates, which were not dissolved at this temperature.

\subsubsection{Strain Hardening and Its Partitioning Between the Present Phases of the Composite}

To characterize the hardening behavior of the composite material during cold forming, interrupted compression tests were performed. The documentation of geometric changes of the specimen shape enabled the calculation of axial, tangential and hydrostatic stress components for the different material states [20]. The hydrostatic stress located close to the circumferential surface of the compression test sample is represented in Fig. 7.5a, which is exemplary of the composite material with a $\mathrm{ZrO}_{2}$ particle distribution between 10 and $30 \mu \mathrm{m}$. The hydrostatic stress is illustrated, which is in fact negative. It is obvious that a significant change in the curve progression starts from $20 \% \mathrm{ZrO}_{2}$ content upwards. The further development of the model according to Pyshmintsev [21] allowed an exact prediction of the strain-induced $\gamma \rightarrow \alpha^{\prime}$ phase transformation from the measured values of the axial strain and the calculated hydrostatic stress. The results showed very good agreement with the experimental values determined with the help of the magnetic balance [5]. Due to the small fraction of the $\mathrm{t}-\mathrm{ZrO}_{2}$ phase in the initial state of the composite after hot pressing, the $t \rightarrow m$ phase transformation was not taken into account. According to the general mixture
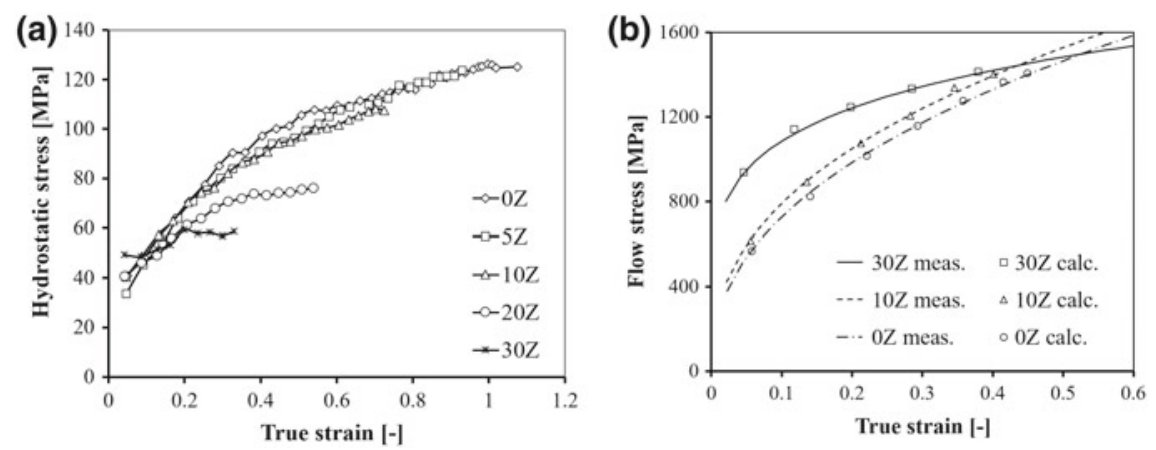

Fig. 7.5 a Variation in hydrostatic stress (negative) for different $\mathrm{ZrO}_{2}$ contents and $\mathbf{b}$ a comparison between the predicted and the measured cold flow curves [5, 6] 
rule by Tamura et al. [22], the flow stress of the composite was defined from the flow stresses of the single microstructural phases, such austenite $\gamma, \alpha^{\prime}$-martensite and $\mathrm{ZrO}_{2}$, as well each phase volume fraction as

$$
\sigma_{\text {mix. }}\left(\varepsilon_{\text {mix. }}\right)=f_{\gamma}\left(\varepsilon_{\text {mix. }}\right) \cdot \sigma_{\gamma}\left(\varepsilon_{\gamma}\right)+f_{\alpha^{\prime}}\left(\varepsilon_{\text {mix. }}\right) \cdot \sigma_{\alpha^{\prime}}\left(\varepsilon_{\alpha^{\prime}}\right)+f_{\mathrm{ZrO}_{2}} \cdot \sigma_{\mathrm{ZrO}_{2}}\left(\varepsilon_{\mathrm{ZrO}_{2}}\right)
$$

under the condition that the sum of all phase volume fractions remains constant at any moment of the deformation

$$
f_{\gamma}\left(\varepsilon_{\text {mix. }}\right)+f_{\alpha^{\prime}}\left(\varepsilon_{\text {mix. }}\right)+f_{\mathrm{ZrO}_{2}}=1 \text {. }
$$

Assuming that the energy density has the same value for each single microstructural constituent and for the whole sample at every moment of the deformation (the so-called ISO-E hypothesis), the flow curves of the composites with different ceramic contents were calculated (Fig. 7.5b). The results showed very good accuracy between the calculated and measured datasets. The specific prediction accuracy of the correlation is $2 \%, 2 \%$ and $1 \%$ for the chosen $\mathrm{ZrO}_{2}$ contents of $0 \%, 10 \%$ and $30 \%$, respectively. Thus, a fast and accurate method was developed for predicting the strain hardening behavior of TRIP-matrix composites under cold deformation conditions [5].

To improve the convergence of calculation based on the mixture rule, the accuracy of the total strain estimates for the composite has to be increased. The mixture strain of the composite is determined by

$$
\varepsilon_{\text {mix. }}=f_{\gamma} \cdot \varepsilon_{\gamma}+f_{\alpha^{\prime}} \cdot \varepsilon_{\alpha^{\prime}}+f_{\mathrm{ZrO}_{2}} \cdot \varepsilon_{\mathrm{ZrO}_{2}}
$$

using the local strains and volume fractions of each phase.

Because the experimental determination of local phase strains is fraught with difficulties [23], the ISO-E method in inverse mode was used. Based on this approach, the relationship between the mixture strain of the composite and the local strain values of each phase was determined (Fig. 7.6). The figure shows that the curves for each phase component are nonlinear. The deformation of austenite in the low mixture strain range of the composite corresponds substantially to the composite strain. With a further increase in the mixture strain of the composite, the local deformation of austenite tends to have higher strain values than the composite. The local strains of martensite and $\mathrm{ZrO}_{2}$ are significantly lower than the mixture strain of the composite.

Based on the calculations performed, a graphical working map was developed to predict the mixture strain of the composite according to the known $\mathrm{ZrO}_{2}$ volume fractions and mixture stress. In Fig. 7.7, an example is illustrated and marked with arrows. For a composite with $10 \% \mathrm{ZrO}_{2}$ and a mixture stress of $900 \mathrm{MPa}$, a mixture strain of the composite $\varepsilon_{\text {mix. }}=0.16$ is determined. On the lower left side, the known $\mathrm{ZrO}_{2}$ content of $10 \%(0.1)$ is used, and the mixture stress gives the value of $\varepsilon_{\mathrm{ZrO} 2}=$ 0.03. On the upper right side, the known mixture stress and the isoline for $\varepsilon_{\mathrm{ZrO} 2}=$ 0.03 are used to find the strain $\varepsilon_{\text {mix. }}=0.16$. 


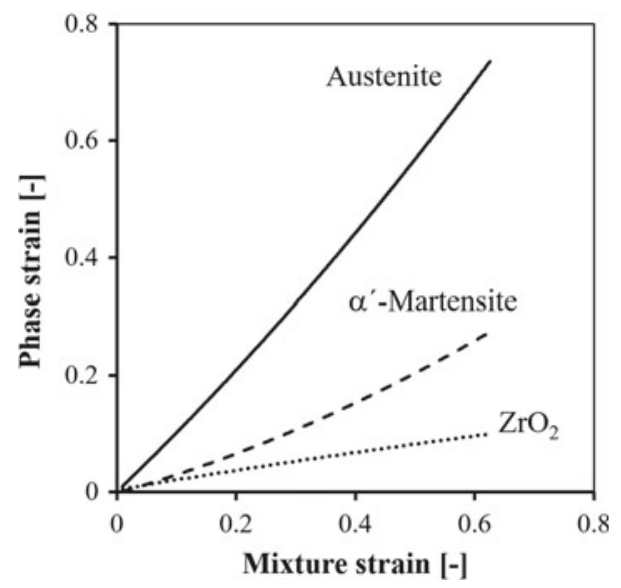

Fig. 7.6 Relationship between the mixture strain of the composite and the local strain values of each phase within the composite under cold forming conditions calculated with the ISO-E method [6]

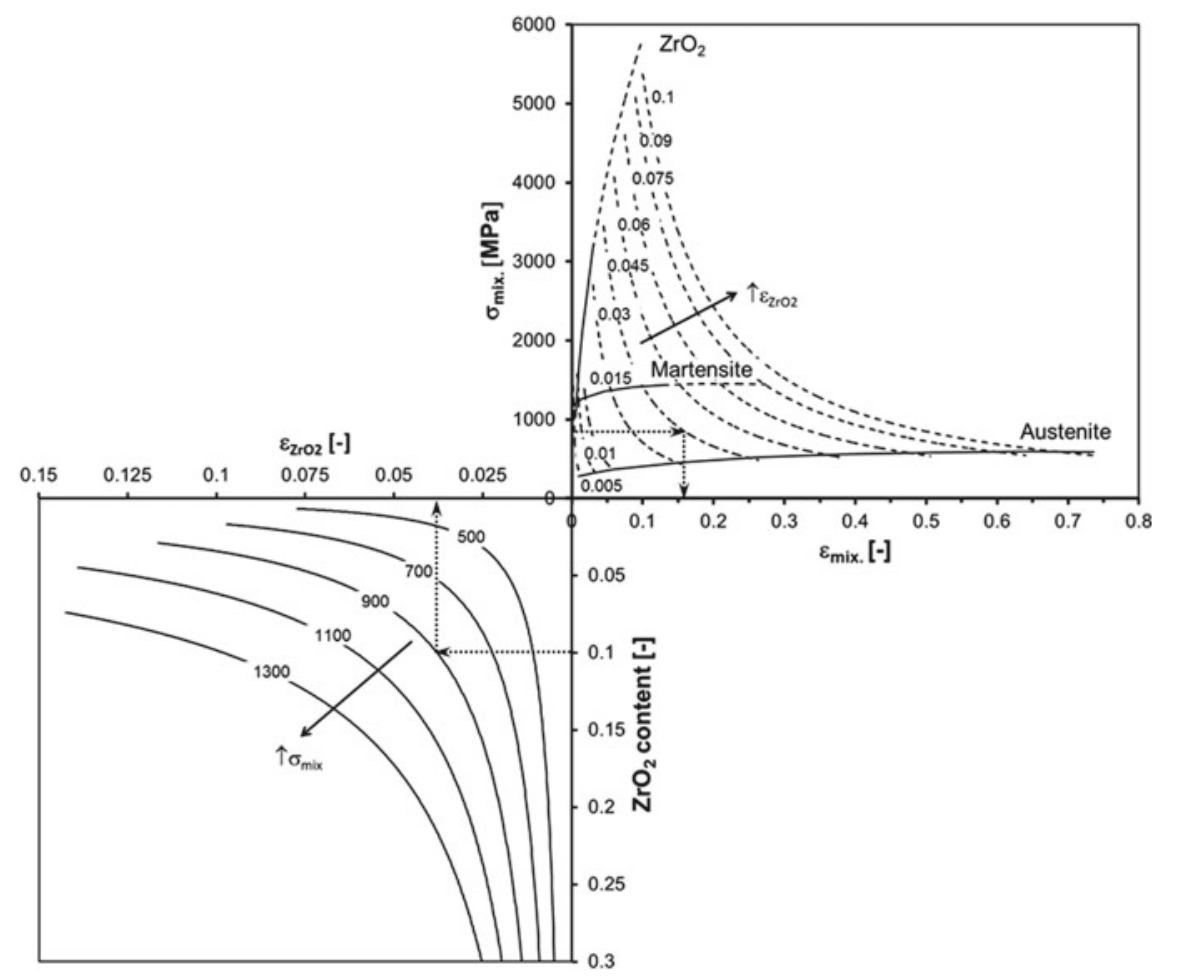

Fig. 7.7 Working map for strain dependence of the composite under cold forming conditions [6] 

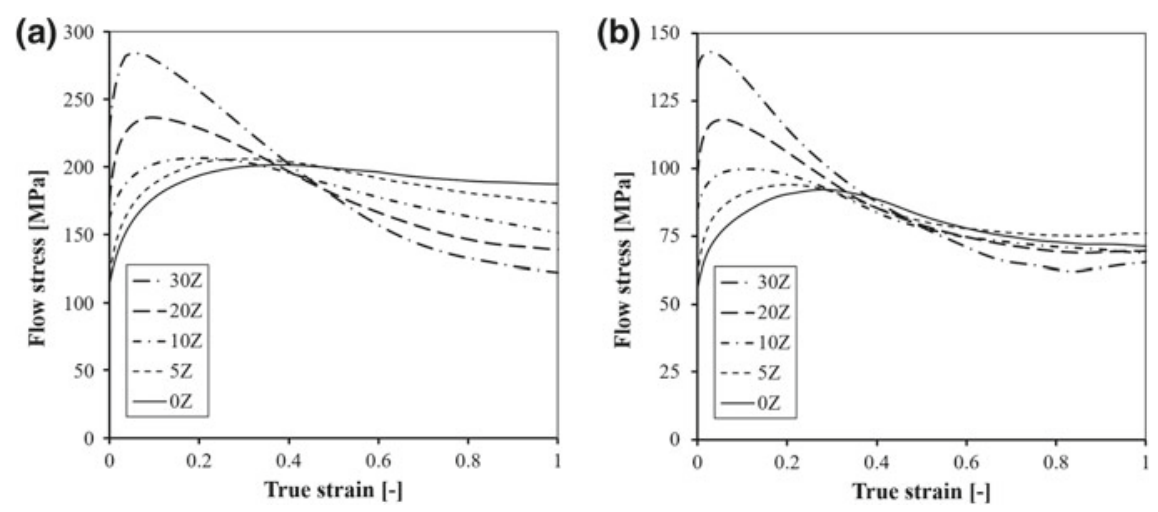

Fig. 7.8 Influence of the $\mathrm{ZrO}_{2}$ content with a particle size less than $10 \mu \mathrm{m}$ on the flow curve at a strain rate of $0.1 \mathrm{~s}^{-1}$ for $\mathbf{a} 900^{\circ} \mathrm{C}$ and $\mathbf{b} 1100{ }^{\circ} \mathrm{C}$

To separate the hot forming temperature region from the cold forming temperature region, investigations were carried out to determine the nonrecrystallization temperature. The results showed that the addition of $\mathrm{ZrO}_{2}$ with the investigated contents and particle distributions had no significant effect on the nonrecrystallization temperature and that this temperature remained at approximately $900{ }^{\circ} \mathrm{C}$. The result is not surprising given the large size of the ceramic particles $(>1 \mu \mathrm{m})$ compared to the hardening phases $(<0.01 \mu \mathrm{m})$ in precipitation hardening alloys of delayed recrystallization kinetics.

Under hot forming conditions, the flow stress was determined as a function of the ceramic content and the technological influencing variables, such as deformation temperature and strain rate. There is no strain-induced $\gamma \rightarrow \alpha^{\prime}$ phase transformation in this temperature region. The $\mathrm{ZrO}_{2}$ content had a considerable influence on the flow curves. Figure 7.8 shows the courses of two flow curves for composite materials with a $\mathrm{ZrO}_{2}$-particle size less than $10 \mu \mathrm{m}$. This figure clearly shows that the hardening at the beginning of the hot deformation is much more pronounced in samples with a high $\mathrm{ZrO}_{2}$ content than in samples with a lower $\mathrm{ZrO}_{2}$ content. Specimens with a $\mathrm{ZrO}_{2}$ content of $30 \%$ reach their maximum flow stress of $280 \mathrm{MPa}$ at a strain of approximately 0.1 . On the other hand, the undoped steel matrix exhibits a flow stress of $177 \mathrm{MPa}$ at this strain value. Thus, the composite exhibits up to $58 \%$ higher flow stress at low strain values. However, this effect is not valid over the entire range of the flow curve. Therefore, from a strain over $0.25-0.4$, the flow stress level of the undoped steel matrix is higher than that of the composite material. At a strain of 1.0, the undoped steel matrix has a flow stress of $185 \mathrm{MPa}$ and the composite material has a flow stress of $120 \mathrm{MPa}$, which corresponds to a decrease of $35 \%$. Thus, the $\mathrm{ZrO}_{2}$ content has a clear influence on the hardening and softening behavior of the composites. The hypothesized reason for the different hardening behavior is that the $\mathrm{ZrO}_{2}$ particles under hot deformation conditions only participate insubstantially in the deformation process (cf. Sect. 7.3.4). Therefore, the applied force must be distributed over a smaller volume. Consequently, the strain in the steel matrix is 
Fig. 7.9 Influence of the $\mathrm{ZrO}_{2}$ content in the composite on its nonrecrystallization temperature

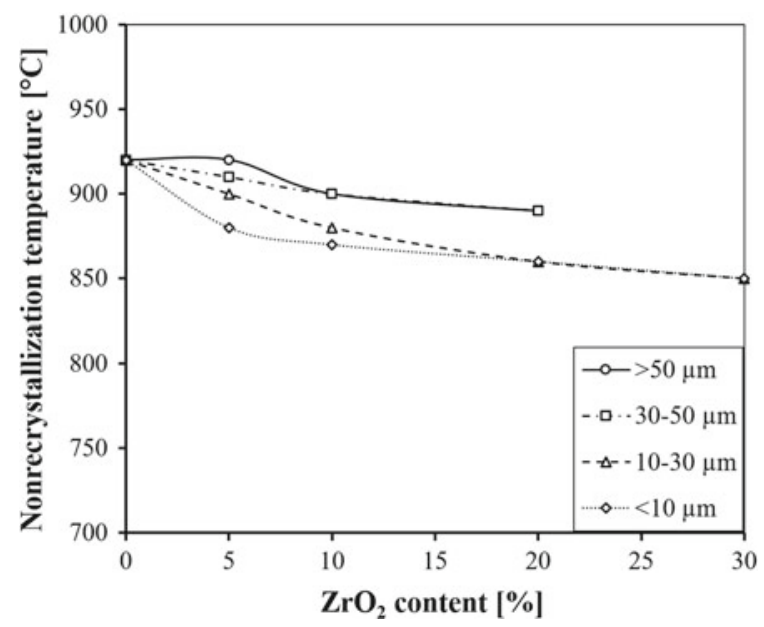

significantly higher than initially assumed. As a result, the strain rate ultimately increases, which leads to faster hardening of the composite material. The higher level of strengthening can also be explained by the deformation-induced $t \rightarrow m$ phase transformation of the $\mathrm{ZrO}_{2}$. Due to this phase transformation, a hydrostatic stress condition occurs that enables higher strains in the matrix, which also leads to higher hardening. By enabling higher strains in the matrix, all samples from 0 to $30 \% \mathrm{ZrO}_{2}$ also achieve similar macroscopic strain values of approximately 1 .

These findings show that the critical strain required for recrystallization beginning is achieved sooner than the macroscopic deformations suggest. This phenomenon is also confirmed by measurements to determine the nonrecrystallization temperature. As the compilation of determined values in Fig. 7.9 shows, the addition of $\mathrm{ZrO}_{2}$ in the investigated contents and particle distributions slightly decreases the nonrecrystallization temperature. The results confirm the hypothesis. Therefore, the flow curves with increased $\mathrm{ZrO}_{2}$ contents exhibit monotonic changes at lower strains. Furthermore, from this point of view, the load-bearing cross-section of the samples changes. The applied force is distributed only over the steel matrix, which ultimately results in a lower flow stress. Figure 7.8a can be used as an example of this behavior. According to this consideration, the load-bearing cross-section of the sample is reduced by the proportion of the $\mathrm{ZrO}_{2}$ content. The undoped steel matrix achieves a flow stress in the steady-state range of approximately $185 \mathrm{MPa}$, and with the addition of $30 \% \mathrm{ZrO}_{2}$, the achievable flow stress also decreases by a similar percentage $(35 \%)$ to $120 \mathrm{MPa}$. The same tendency can also be seen in Fig. 7.8b.

On the basis of the determined influence of the $\mathrm{ZrO}_{2}$ content on the characteristics of the hot flow curves of the composite, a modification of the well-known Freiberg flow curve approach for homogeneous conventional materials was carried out so that the $\mathrm{ZrO}_{2}$ content was taken into account. Since the influence of the strain rate is not important for the consideration of the dependence of the $\mathrm{ZrO}_{2}$ content, this factor was not implemented in the calculation of the flow curves. The basic prerequisite 
for the approximation of the hot flow curves was the Freiberg approach number 4 according to the form [9]

$$
\sigma_{\text {mix. }}=A \cdot \mathrm{e}^{m_{1} \cdot T} \cdot \varepsilon^{m_{2}} \cdot \mathrm{e}^{\frac{m_{4}}{\varepsilon}} \cdot(1+\varepsilon)^{m_{5} \cdot T} \cdot \mathrm{e}^{m_{7}}
$$

To adapt the Freiberg approach to the deformation conditions of the composite materials, this approach was modified by adding four factors. At first, this is the $\mathrm{ZrO}_{2}$ content $Z$. With increasing $Z$, the hardening of the composite material also increases; thus, the factor $\varepsilon^{m_{2}}$ changes to $\varepsilon^{m_{2} \cdot Z}$, and the factor $(1+\varepsilon)^{m_{5} \cdot T}$ changes to $(1+\varepsilon)^{m_{5} \cdot T \cdot Z}$. After reaching the critical strain for the beginning of recrystallization, the softening factor is also influenced and results in $\mathrm{e}^{\frac{m_{4}}{\varepsilon} \cdot Z}$. Moreover, the Freiberg approach was extended by an e-function for a better approximation in the range of increased strains and by two exponential functions dependent on $\varepsilon$ and $Z$, which take into account the increased strain hardening. This resulted in a modified Freiberg approach for hot deformation of composite materials, which is expressed as

$$
\sigma_{\text {mix. }}=A \cdot \mathrm{e}^{m_{1} \cdot T} \cdot \varepsilon^{m_{2}} \cdot \mathrm{e}^{\frac{m_{4}}{\varepsilon}} \cdot(1+\varepsilon)^{m_{5} \cdot T} \cdot \mathrm{e}^{m_{7} \cdot \varepsilon} \cdot \varepsilon^{m_{11} \cdot Z} \cdot \mathrm{e}^{m_{12} \cdot Z} \cdot(1+\varepsilon)^{m_{13} \cdot Z \cdot T}
$$

Table 7.3 shows, for example, the coefficient and exponents determined for $\mathrm{ZrO}_{2}$ particle sizes below $10 \mu \mathrm{m}$. Moreover, the modified Freiberg flow curve approach also provides a very high coefficient of determination and a small standard deviation for a $\mathrm{ZrO}_{2}$ content of $0 \%$.

Based on the modified Freiberg flow curve approach, the flow curves were then calculated using a combination of the ISO-E method and the mixture rule. Assuming that the energy density in the steel matrix and in the $\mathrm{ZrO}_{2}$ particles is the same during the deformation of the composite material, the area integrals of the hot flow

Table 7.3 Parameters for the modified Freiberg flow curve approach for hot deformation of

\begin{tabular}{|c|c|c|c|c|}
\hline Parameter & Value & $\mathrm{ZrO}_{2}$ content, $\%$ & $\begin{array}{l}\text { Coefficient of } \\
\text { determination }\end{array}$ & $\begin{array}{l}\text { Standard deviation, } \\
\text { MPa }\end{array}$ \\
\hline$A$ & 4559.889 & \multirow[t]{2}{*}{0} & \multirow[t]{2}{*}{0.977} & \multirow[t]{2}{*}{16.90} \\
\hline$m_{1}$ & -0.002793 & & & \\
\hline$m_{2}$ & 0.285427 & \multirow[t]{2}{*}{5} & \multirow[t]{2}{*}{0.987} & \multirow[t]{2}{*}{11.50} \\
\hline$m_{4}$ & 0.000837 & & & \\
\hline$m_{5}$ & -0.001802 & \multirow[t]{2}{*}{10} & \multirow[t]{2}{*}{0.997} & \multirow[t]{2}{*}{4.10} \\
\hline$m_{7}$ & 0.424686 & & & \\
\hline$m_{11}$ & -0.187844 & \multirow[t]{2}{*}{20} & \multirow[t]{2}{*}{0.989} & \multirow[t]{2}{*}{12.40} \\
\hline$m_{12}$ & 1.330402 & & & \\
\hline \multirow[t]{2}{*}{$m_{13}$} & \multirow[t]{2}{*}{0.00485} & 30 & 0.987 & 15.10 \\
\hline & & 100 & 0.983 & 51.50 \\
\hline
\end{tabular}
composites with particle sizes $<10 \mu \mathrm{m}$ (valid for temperatures between 900 and $1200{ }^{\circ} \mathrm{C}$ ) 
Fig. 7.10 Relationship between the mixture strain of the composite and the local strain values of each phase within the composite under hot deformation conditions calculated with the ISO-E method

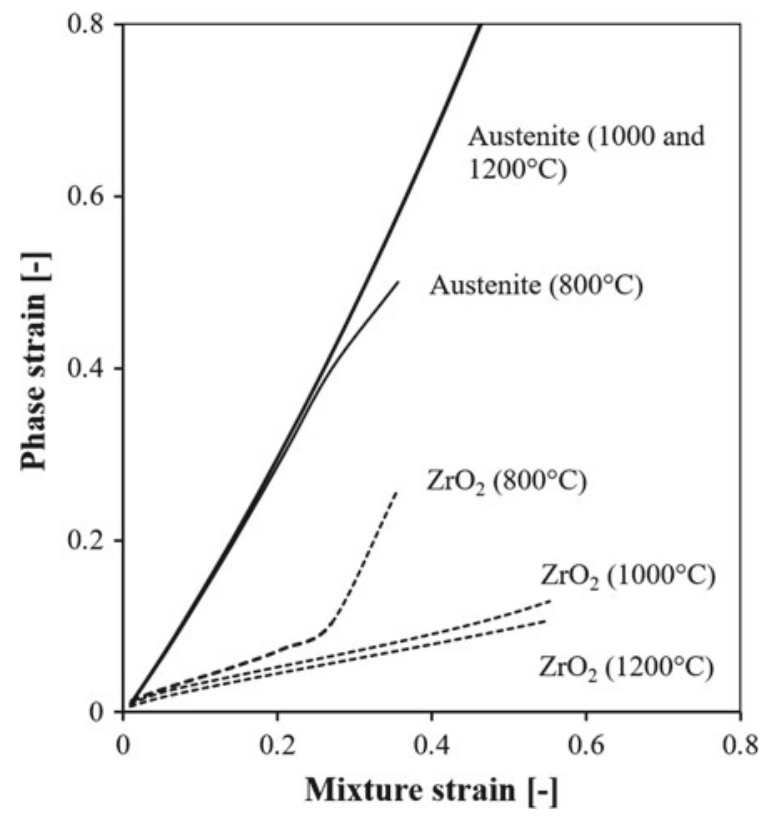

curves of the steel and the ceramic can also be equated. The integration limits $\varepsilon_{1}$ and $\varepsilon_{2}$ are the strains here. By means of a previous determination of the equations for flow stress using the modified Freiberg approach, it was now possible to calculate the corresponding strain of $\mathrm{ZrO}_{2}$ by specifying a strain for the steel matrix. The strain dependencies for the three selected temperatures are shown in Fig. 7.10. This figure clearly shows that the specification of the ISO-E method at low temperatures imposes very high strains on the $\mathrm{ZrO}_{2}$. Even at higher temperatures and high steel matrix strains, the $\mathrm{ZrO}_{2}$ achieves strains that are significantly higher than the strains from the compression tests. The flow stresses calculated using the mixture rule were compared with the measured values. This comparison shows that the calculated flow stresses exceed the actual flow stresses by up to $600 \%$.

The reasons for the large deviations are diverse and can be justified by the mixture rule. For example, by equating the area below the flow curve (energy density), the $\mathrm{ZrO}_{2}$ is forced to deform to an excessively high strain, or the steel matrix is not loaded to failure. This results from the fact that if a high strain is specified for the steel matrix, the integral also assumes very high values. However, these can only be equalized by means of high $\mathrm{ZrO}_{2}$ strains.

This finding shows that the deformation in the high temperature range is not divided among the present phase components but nearly exclusively among the steel matrix. Thus, the assumption of an evenly distributed energy density regarding the deformation of steel and ceramics at high temperatures can be rejected.

Another approach would be to consider the composite as a viscous fluid with hard inclusions. The maximum stress the composite can withstand is the flow stress of 
the steel matrix. As a result, the $\mathrm{ZrO}_{2}$ particles cannot be subjected to higher stresses than the matrix. This aspect is completely ignored by the ISO-E method. For this consideration, only the volume fraction of the $\mathrm{ZrO}_{2}$ is decisive for the development of the flow curve. Thus, a high $\mathrm{ZrO}_{2}$ content corresponds to a low matrix content, which leads to a lower flow stress because the deformation is only localized in the matrix.

This approach is of course not suitable for very high $\mathrm{ZrO}_{2}$ contents. As soon as the particles "touch" each other and form a kind of "skeleton" in the matrix, they can also absorb a portion of the applied stress, thereby contributing significantly to the hardening of the composite. On the other hand, a small fraction of $\mathrm{ZrO}_{2}$ means a higher flow stress because more material is available to cope with the stress.

In conclusion, the presented modified Freiberg approach is the most advantageous variant with regard to the modeling of hot flow curves of composite materials. The ISO-E method does not provide any useful results due to errors caused by a principle calculation assumption.

\subsubsection{Strain Softening}

The dynamic softening behavior was analyzed on the basis of warm flow curves (cf. Fig. 7.8). All measured hot flow curves have a maximum value and then decrease continuously with increasing strain due to dynamic recovery and recrystallization processes. As the shape of the flow curves shows, dynamic recrystallization and dislocation hardening are the determining processes during hot deformation. One of the main reasons for this phenomenon is the low stacking fault energy of the face-centered cubic (FCC) crystal structure of the steel matrix [24].

The $\mathrm{ZrO}_{2}$ particles represent barriers to dislocation movement in the hardening processes due to faster and higher hardening values. After exceeding the critical flow stress, the new grains form near the $\mathrm{ZrO}_{2}$ particles due to the increased dislocation density in these locations. Compared to the undoped steel matrix, the addition of $\mathrm{ZrO}_{2}$ to the composite material creates an additional grain boundary surface, which favors the formation of new grains. Therefore, the softening processes run faster in composite materials (cf. Fig. 7.8) [25].

Figure 7.11a shows exemplary results from modeling dynamic softening on the basis of reaction kinetic calculation equations. The model calculation shows that a largely complete dynamic recrystallization can only be achieved at higher strains of approximately 1.5. In contrast, the influence of temperature is less pronounced in the investigated area and causes faster dynamic softening only in the medium strain range with increasing temperature. This effect can be explained by thermal activation.

The static softening behavior was measured by means of double compression tests. In the entire investigated temperature and strain rate range, the composite material showed a sigmoidal softening process. As expected, static softening occurred faster with increasing strain rate and rising deformation temperature. The results indicated 

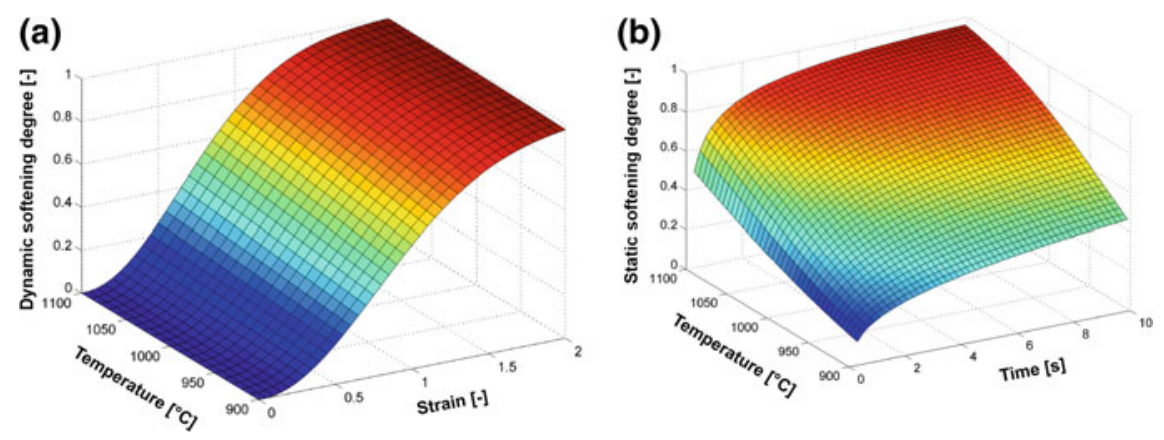

Fig. 7.11 a Dynamic and $\mathbf{b}$ static softening kinetics of composite material with $10 \% \mathrm{ZrO}_{2}$ as a function of deformation temperature, strain and pause time at a strain rate of $1 \mathrm{~s}^{-1}$

that the $\mathrm{ZrO}_{2}$ particles present in the composite material significantly accelerate the processes of static softening compared to the undoped steel matrix.

The investigations have contributed to the development of a model for static softening based on kinetic reaction equations. Figure 7.11 shows exemplary results from modeling the composite material with $10 \% \mathrm{ZrO}_{2}$ at a strain rate of $1 \mathrm{~s}^{-1}$. An increase in temperature from 900 to $1100{ }^{\circ} \mathrm{C}$ at a constant pause time of $10 \mathrm{~s}$ led to a doubling of the static softening degree, resulting in a completely recrystallized microstructure.

\subsubsection{Formability}

Transverse extrusion tests were used to characterize the cold formability of the composite materials with different $\mathrm{ZrO}_{2}$ contents. Figure $7.12 \mathrm{a}$ shows an example of the change in cold formability for the ceramic particle distribution of 10-30 $\mu \mathrm{m}$, wherein the values are normalized to the formability of the undoped steel matrix. The results indicate that the normalized cold formability decreases nearly hyperbolically with increasing $\mathrm{ZrO}_{2}$ content in the composite material. For ceramic phase contents below $20 \%$, the normalized cold formability decreases by approximately $2.5 \%$ per $1 \%$ increase in ceramic content. This trend correlates well with the decreasing content of transformed $\alpha^{\prime}$-martensite and subsequently with the decreasing value of macroscopic residual compressive stresses generated in front of the crack tip, which increase the crack propagation velocity. The decreasing cold formability is visible in the changing appearance of the cracked flange area of the specimen after failure. Figure 7.12a shows that the increase in the ceramic content leads to an increasing number of small radial macrocracks, which developed under the effect of tangential tensile stresses starting from the specimen flange edge. Considering the fact that microcracks always occur at the largest microstructural inhomogeneities [26], which in this case is at the $\mathrm{ZrO}_{2}$ particles, at high ceramic contents, there is always 

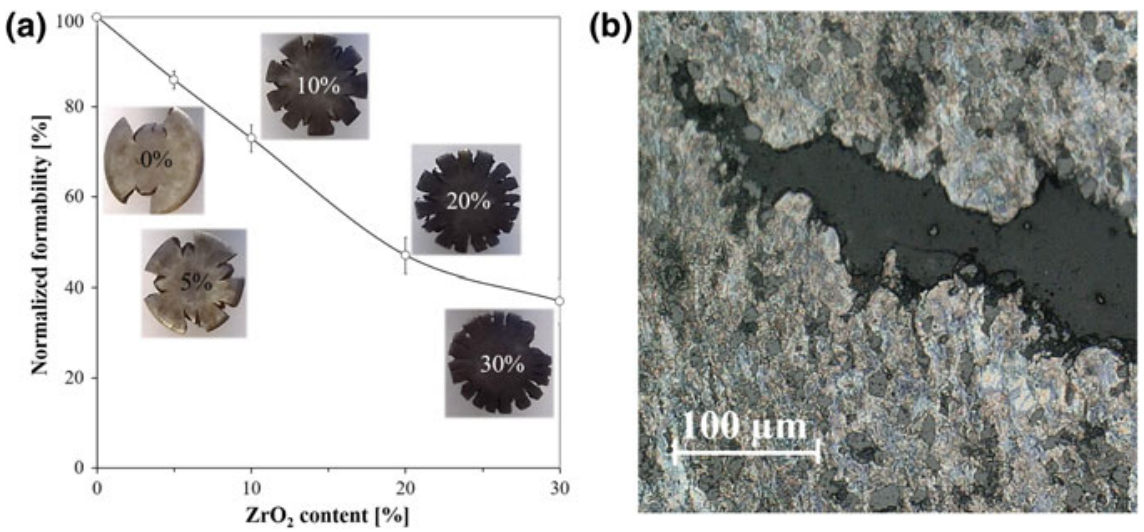

Fig. 7.12 a Development of the normalized cold formability with increasing $\mathrm{ZrO}_{2}$ content determined by means of transverse extrusion tests with appearances of the cracked flange area of the specimen after failure. b Image of a macrocrack on the flange area of the specimen with $20 \% \mathrm{ZrO}_{2}$, in which the $\mathrm{ZrO}_{2}$ particles are shown in light gray and the pores are shown in black

at least one large particle at the edge of the sample where the maximum tangential tensile stresses are acting during deformation. Due to the strain obstruction, stress concentrations occur at these points in the steel matrix in the vicinity of the ceramic particles. These stress concentrations lead to cracking in the steel matrix near the phase interfaces. Once local damage occurs, crack propagation initiates under the acting tangential tensile stress. Here, the free path length between ceramic particles determines the size of the damage zone in front of the growing crack, in which mainly the steel matrix fails at the phase interface (Fig. 7.12b). The positive phenomenon of the failure by means of delamination at the phase boundary is reflected in the decreasing crack propagation velocity in the steel matrix because the pores formed by the delamination locally increase the multiaxiality and slow the crack propagation, which occurs through local plastic deformation. The microcracks formed in this way quickly combine to form a larger macrocrack, the growth rate of which is ultimately determined by the hardness and toughness of the steel matrix. Figure $7.12 \mathrm{~b}$ shows that the microcracks also grow outside the main crack path. There, energy is converted, which does not serve the propagation of the main crack. The results show that when the $\mathrm{ZrO}_{2}$ content is $30 \%$, more ceramic particles are located in the damage zone, thereby inhibiting the crack propagation velocity through the formation of secondary cracks and crack branching. With a constant ceramic content in the microstructure, the crack propagation velocity decreases with increasing particle size because the free path length between two $\mathrm{ZrO}_{2}$ particles increases. Based on the investigations, it was possible to limit the maximum $\mathrm{ZrO}_{2}$ content for cold rolling processes to $10 \%$ due to an increased risk of edge cracking.

The hot formability was characterized according to the methodology in [16] based on the measured hot flow curves. The resulting calculation of process maps made it 

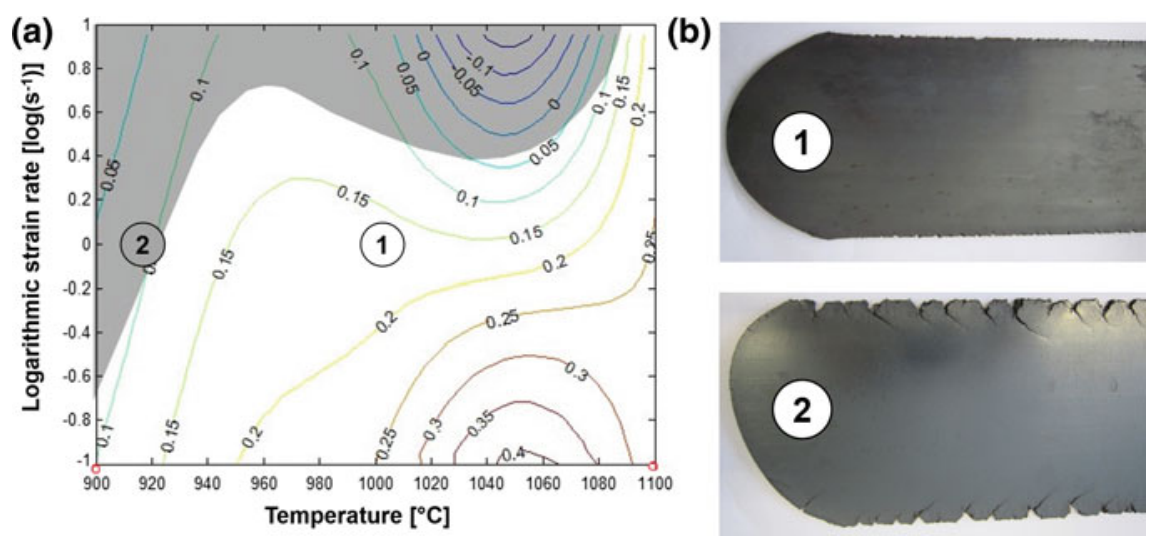

Fig. 7.13 a Process map for hot deformation conditions of composite with $10 \% \mathrm{ZrO}_{2}$ and strain of 0.3 and $\mathbf{b}$ the validation results after hot rolling

possible to determine the optimum process window from the point of view of failurefree deformation. Figure 7.13a shows an exemplary process map for the composite material with $10 \% \mathrm{ZrO}_{2}$ content for a strain of $\varepsilon=0.3$ in the temperature interval of $900-1100{ }^{\circ} \mathrm{C}$ and the strain rate interval of $0.1-10 \mathrm{~s}^{-1}$. The bright and gray areas of the map correspond to stable (fracture free) and unstable deformation, respectively. The values at the isolines reflect the efficiency of the dissipation process. One part of the energy used for deformation gets lost (for example, due to heating) and is not available for the dynamic recovery, the dynamic recrystallization, the closing of pores and so on. A comparison of the process maps and the experimental data of all investigated composites showed their dependence on the different deformation conditions. It was obvious that some combinations of strain rate, temperature and composite microstructure led to failure (gray areas of the maps; for example, position 2 in Fig. 7.13a). The technological combinations reflected the main role of $\mathrm{ZrO}_{2}$ content and coarse particle fraction during the deformation process. However, it was deduced that at the lowest investigated deformation temperatures of 700 and $800{ }^{\circ} \mathrm{C}$, failure is only slightly influenced by the increased $\mathrm{ZrO}_{2}$ content. Here, an increased risk of failure already occurred in the course of strain hardening. The best hot deformation conditions for the investigated temperatures of 900 and $1100{ }^{\circ} \mathrm{C}$ are at a maximum strain rate of approximately 0.2 and $10 \mathrm{~s}^{-1}$, respectively (cf. position 1 in Fig. 7.13a). It is obvious that the agglomerates lead to failure, and the increase in deformation temperature extends the interval of failure strains. Regarding the initial material condition, it was shown — analogous to cold deformation — that composite materials with finer ceramic particles are significantly more sensitive to material failure due to the reduced free path length between ceramic particles for the same ceramic content. Further investigations using light microscopy and SEM confirmed interfacial delamination as the cause of failure. The results showed that, from the point of view of thermomechanical treatment, only conventional rolling in the high 
temperature range is suitable for achieving sufficient formability of the composite material [27].

\subsubsection{Material Flow During Rolling}

Investigations on the deformation behavior and the quantitative microstructure analysis showed that after a rolling reduction of approximately $30 \%$, the porosity was eliminated in all composites. Furthermore, the results show that the number of pores is accompanied by an agglomeration affinity of the composite. It is important to mention that the composites with high rates of agglomerates have twice the number of pores than found in the initial state in the case of maximal deformation. This behavior can be explained with the help of a model, which is qualitatively shown in Fig. 7.14. There are large pores around single $\mathrm{ZrO}_{2}$ agglomerates in the initial state, which are still present on the phase borders because of insufficient sintering results (Fig. 7.14a). As elaborated in [28], the larger particles of irregular shape produce a greater effect on the local curvature, especially at lower deformation. The angular component of the deformation tensor can be evaluated at the turning of phase and grain boundaries and has a higher influence on inhomogeneous deformation. The primarily common plasticization of the steel matrix is promoted, and the realignment of $\mathrm{ZrO}_{2}$ particles is observed. This process is the initial phase of local plastic deformation, which can create local bonding between composite phases according to their form and structure. The local inhomogeneity of deformation promotes local flow stress. The initial large pores can split into many small pores (Fig. 7.14a) and move or align in the direction of local stress together with the grain boundaries, phase boundaries, and agglomerates. The changeable influence of the composite microstructure on the evolution of the number of pores confirms the reality of a qualitative model [27].

Furthermore, the results show that reorientation of single $\mathrm{ZrO}_{2}$ particles with partial line formation depends on the agglomeration grade of the composite. This behavior applies to the less agglomerated composites and is related to single enclosed $\mathrm{ZrO}_{2}$ particles or to the small line groups (clusters) consisting of 4-8 particles. Their arranged length is correlated to the austenite grain size during plasticization of the steel matrix (Fig. 7.14b). In contrast, a destruction of large agglomerates could not be revealed.

Regarding the material flow and the particle rearrangement resulting from deformation, metallographic investigations were carried out on sheets and on the compression, wedge rolling and stuck rolling specimens. The light microscopy images were examined based on quantitative metallographic parameters. Thus, the determined anisotropy index AI provides information on the homogeneous distribution of the particles. For the same strain value, no influence of particle size, deformation temperature or deformation zone geometry on AI was determined for the hot-compressed specimens. In contrast, investigations on the wedge rolling specimens showed that the particle distribution in the composite material becomes anisotropic with increasing 


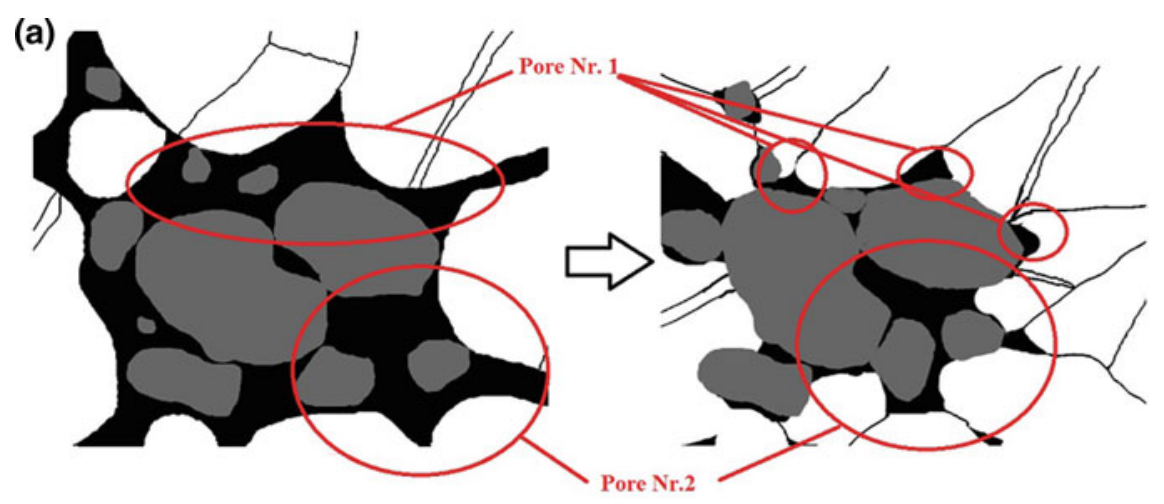

(b)

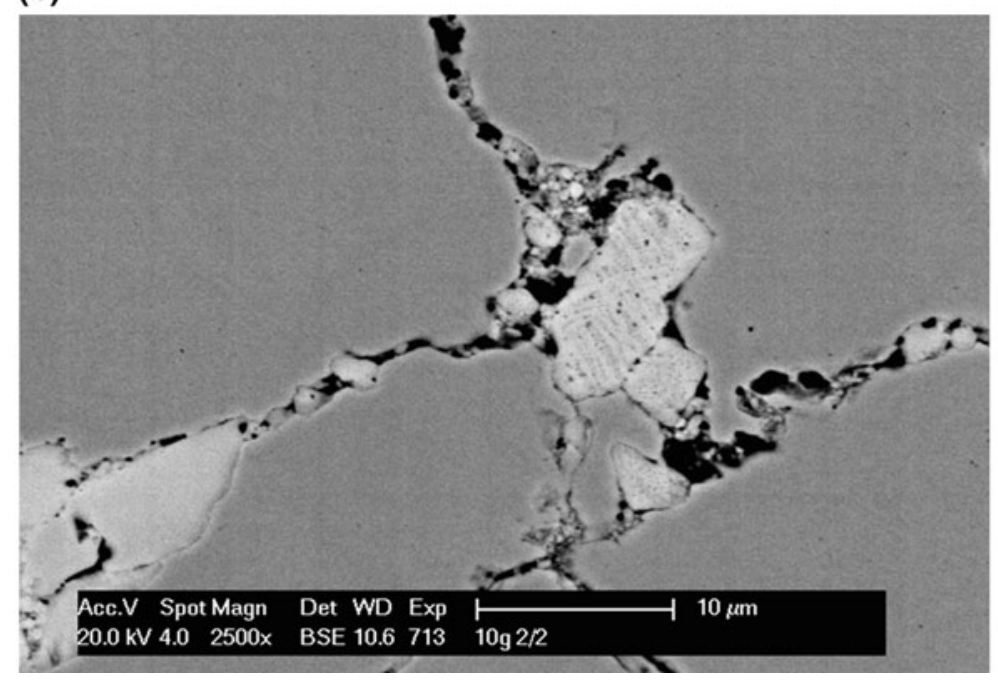

Fig. 7.14 a Qualitative model of the deformation behavior around a $\mathrm{ZrO}_{2}$ agglomerate and b realignment of $\mathrm{ZrO}_{2}$ particles [27]

strain. The corresponding increase in anisotropy depended primarily on the deformation temperature. A further characterization of the material flow during deformation with regard to a preferred direction of the particles is given by the degree of orientation $\Omega_{12}$. This value also increased with increasing strain (Fig. 7.15a). This finding supported the conclusion that the ceramic particles move with the flowing steel matrix as a result of the deformation and align in the flow direction (cf. Sect. 7.3.2 and Fig. 7.15b) [29]. 

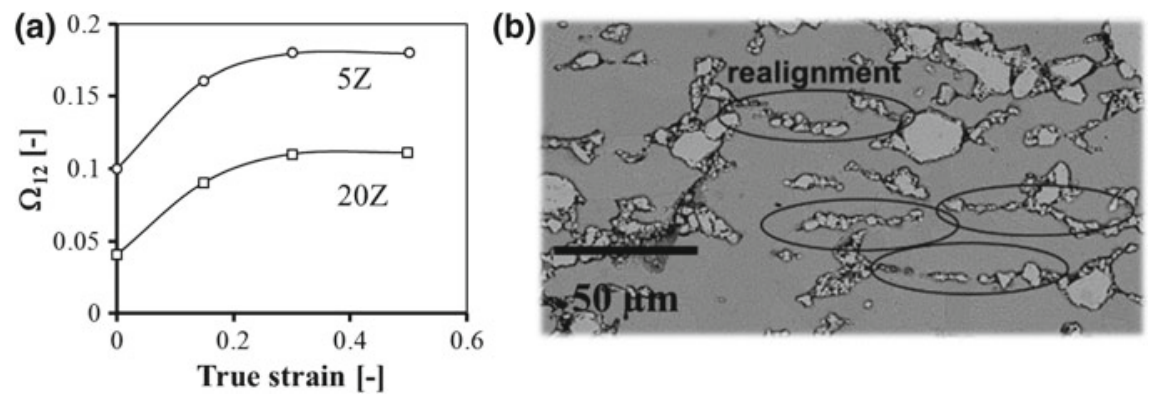

Fig. 7.15 a Development of the degree of orientation $\Omega_{12}$ of $\mathrm{ZrO}_{2}$ particles with respect to the true strain for composites with 5 and $20 \% \mathrm{ZrO}_{2}$ and $\mathbf{b}$ the realignment (line) formation in the microstructure after hot rolling with a thickness reduction of $45 \%[27,29]$

\subsection{Conclusions}

Currently, models are increasingly being used to perform computer simulations of material manufacturing and further processing from semifinished products to finished parts and to predict the mechanical properties of the finished components. In this chapter, the deformation behavior of the TRIP-matrix composite under conditions similar to flat rolling in a wide temperature range was tested and analyzed using current test methods. The initial material was available in the presintered form with different ceramic contents between 0 and $30 \%$ and with closely spaced particle sizes between approximately 2 and $60 \mu \mathrm{m}$ (classified by wind sifting) in the high-alloy austenitic steel matrix.

In the field of cold deformation, interrupted compression tests were carried out. The registration of geometrical changes in the specimen shape enabled the calculation of axial, tangential and hydrostatic stress components for different material states. These were implemented in the flow curve modeling. A comparison with the experimental results showed that the prediction accuracy is very good. In further calculations, it was possible to create a flow stress work map for materials with different compositions, where a prediction of local phase strain is possible from the measured macroscopic strain in the composite material.

In the field of hot deformation, technological parameters such as the deformation temperature and the strain rate showed effects on the flow stress level already known from conventional materials. The influence of the varying material condition at constant deformation conditions was expressed as follows. The increase in the $\mathrm{ZrO}_{2}$ content at constant particle size generally leads to an increase in flow stress. The finer the $\mathrm{ZrO}_{2}$ particles are, the greater the increase in flow stress. The deformation temperature has the primary influence and the strain rate has a secondary influence. Based on the determined influence of the $\mathrm{ZrO}_{2}$ content on the characteristics of the hot flow curves of the composite material, the well-known Freiberg flow curve approach for homogeneous materials was modified so that the $\mathrm{ZrO}_{2}$ content was taken into account. For a $\mathrm{ZrO}_{2}$ content of $0-100 \%$, this modified approach provided a very high 
coefficient of determination and a small standard deviation. Based on the Freiberg flow curve approach, the flow curves were then modeled using a combination of the ISO-E method and the mixture rule. This method did not provide any useful results due to errors caused by a principle assumption that is applicable in the determination of cold flow curves but cannot be applied in the area of hot forming.

The analysis of the measured flow curves enabled the following interpretation of the dynamic hardening and softening processes. At temperatures up to $800{ }^{\circ} \mathrm{C}$, softening occurs exclusively through recovery, whereby the flow curve does not pass through a maximum. Above this deformation temperature, dynamic recrystallization appears to be the dominant softening mechanism. The $\mathrm{ZrO}_{2}$ content has the primary influence and the particle size has a secondary influence on the critical strain. The latter decreases with increasing ceramic content and finer particle size.

Transverse extrusion tests were used to characterize the cold formability of the composite materials with different $\mathrm{ZrO}_{2}$ contents. The results indicated that the normalized cold formability decreased hyperbolically with increasing $\mathrm{ZrO}_{2}$ content in the composite material. This trend correlated well with the decreasing fraction of transformed $\alpha^{\prime}$-martensite and subsequently with the decreasing value of the resulting macroscopic residual compressive stresses in front of the crack tip, which increased the crack propagation velocity. The results showed that if the $\mathrm{ZrO}_{2}$ content was $30 \%$, more ceramic particles were in the damage zone, thereby inhibiting the crack propagation velocity through secondary crack formation and crack splitting. With a constant ceramic content in the microstructure, the crack propagation velocity decreased with increasing particle size because the free path length between two $\mathrm{ZrO}_{2}$ particles increased.

Based on the measured flow curves, the optimum process window was determined from the point of view of failure-free deformation by creating process maps in accordance with the methodology reported in [30]. It could be deduced that at the lowest investigated deformation temperatures of 700 and $800{ }^{\circ} \mathrm{C}$, failure was only slightly influenced by the $\mathrm{ZrO}_{2}$ content. Here, an increased risk of failure already occurred in the course of strengthening. With regard to the condition of the material, it can be seen that composite materials with finer ceramic particles at the same ceramic content were significantly more sensitive to material failure. Further investigations using light microscopy and SEM confirmed that interfacial delamination between phases was the cause of failure. Furthermore, the results showed that, from the point of view of thermomechanical treatment, only conventional rolling was suitable for achieving sufficient formability of the composite material in a wide temperature-strain rate window.

With regard to the material flow and the particle rearrangement caused by deformation, metallographic examinations of sheets and the upsetting, wedge rolling and stuck rolling specimens were carried out. These examination quantitatively verified that the ceramic particles move with the flowing matrix material as a result of the deformation and align in the direction of flow. An influence of the deformation temperature within a constant strain value could not be verified. 
Acknowledgements The authors are grateful to the employees of the Fraunhofer Institute for Ceramic Technologies and Systems $(*)$ and of the Institute for Metal Forming $(* *)$, who participated in the powder separation, presintering and rolling processes: Dr. rer. nat. habil. Mathias Herrmann (*), Dipl.-Ing. Jan Räthel (*), Dr.-Ing. Katja Pranke (**) and Dr.-Ing. Wolfhart Müller (**). Special thanks are addressed to Dr. Gizo Bokuchava from the Joint Institute for Nuclear Research, Dubna, Russia, for the execution of the neutron diffraction studies. The authors gratefully acknowledge the German Research Foundation (DFG) for supporting the Collaborative Research Center TRIPMatrix-Composites (Project number 54473466-CRC799 subproject A6).

\section{References}

1. R. Kawalla, A. Nam, S. Guk, Technological methods to control the final properties of the rolled product. J. Chem. Tech. Metall. 50(6), 606-612 (2015)

2. S. Guk, K. Pranke, R. Kawalla, Modeling of properties of sheet metal products from the TRIPmatrix-composite along the process chain. Postersession im Rahmen der 5. ICAFT/22. SFU Tagung vom 10. bis 11. November 2015 am Fraunhofer-Institut für Werkzeugmaschinen und Umformtechnik IWU in Chemnitz

3. F. Qayyum, S. Guk, M. Schmidtchen, R. Kawalla, U. Prahl, Modelling and understanding the deformation behaviour of TRIP steel at microstructural level using DAMASK. Konferenz MEFORM2019 “Simulationsbasierte Technologieentwicklung”, Freiberg, den 20.-21.03.2019

4. A. Yanina, S. Guk, W. Müller, R. Kawalla, C. Weigelt, Herstellung und Weiterverarbeitung von TRIP-fähigen Partikelverbundwerkstoffen. Tagungsband der internationalen Konferenz MEFORM 2012 "Material technology and forging processes". ISBN 978-3-86012-434-5, Freiberg 28.03.-30.03.2012, pp. 216-231

5. S. Guk, K. Pranke, W. Müller, Flow curve modelling of an Mg-PSZ reinforced TRIP-matrixcomposite. ISIJ Int. 54(10), 2416-2420 (2014)

6. S. Guk, W. Müller, K. Pranke, R. Kawalla, Mechanical behaviour modelling of an Mg-stabilized zirconia reinforced TRIP-matrix-composite under cold working conditions. Mater. Sci. Appl. 5, 812-822 (2014)

7. S. Solhjoo, R. Ebrahimi, Prediction of no-recrystallization temperature by simulation of multipass flow stress curves from single-pass curves. J. Mater. Sci. 45, 5960-5966 (2010)

8. S. Vervynckt, K. Verbeken, P. Thibaux, Y. Houbaert, Evaluation of the austenite recrystallization by multideformation and double deformation tests. Steel Res. Int. 82(4), 369-378 (2011)

9. T. Spittel, M. Spittel, Ferrous alloys (2009)

10. C. Biegus, Anwendung von Werkstoffmodellen auf das Entfestigungsverhalten und die Ferritkorngröße mikrolegierter Baustähle. Diss (1996)

11. F. Bubeck, Charakterisierung und Modellierung der Gefügeentwicklung bei der Warmumformung von Kupferwerkstoffen (Diss, TU Bergakademie Freiberg, 2007)

12. W. Müller, Temperaturverhältnisse und Reaktionskinetik beim Ziehen und Wärmebehandeln von Draht. Bd. B292. TU Bergakademie Freiberg (1998)

13. H.-P. Schmitz, Entfestigungsverhalten kohlenstoffarmer Stähle bei der Warmumformung im Ferritgebiet. Diss. Freiberger Forschungshefte B307, TU Bergakademie Freiberg (2000)

14. S. Guk, R. Kawalla, Prozessnahe Beurteilung der Umformbarkeit beim Kaltfließpressen. MassivUmformung (März 2017) pp. 64-68. ISSN 2366-5106

15. F. Qayyum, S. Guk, R. Kawalla, U. Prahl, Experimental investigations and multiscale modeling to study the effect of Sulphur content on formability of $16 \mathrm{MnCr} 5$ alloy steel. Steel Res. Int. (2018). https://doi.org/10.1002/srin.201800369

16. Y.V.R.K. Prasad, T. Seshacharyulu, Modelling of hot deformation for microstructural control. Int. Mater. Rev. 43(6), 243-258 (2013) 
17. S. Guk, D. Plotnikova, R. Kawalla, The effect of microstructural and geometric inhomogeneities induced by laser for forming strain analysis on sheet metal formability. Mater. Sci. Appl. 7, 247-256 (2016)

18. S. Guk, M. Preiß, R. Kawalla, Metal formability interactions in laser marking for creating of grid patterns for forming strain analysis of high strength steels. Key Eng. Mater. 746, 92-98 (2017)

19. S. Guk, K. Pranke, W. Müller, A. Yanina, Development of high-strength TRIP-matrixcomposite materials, in Proceedings of the International Conference of Production and Processing of Cladded Materials and Metal Matrix Composites MEFORM 2014, ISBN 978-3-86012-481-9, Altenberg 26.03.-27.03.2014, Herausg.: ACATRAIN e.V., Verein für Weiterbildung an der TU Bergakademie Freiberg, Institut für Metallformung, pp. 149-159

20. M. Abdel-Rahman, M.N. El-Sheikh, Workability in forging of powder metallurgy compacts. J. Mater. Process. Technol. 54, 97-102 (1995)

21. I. Pyshmintsev, M. Meyer, B. Cooman, R. Savray, V. Shveykin, M. Vermeulen, The influence of the stress state on the plasticity of transformation induced plasticity-aided steel. Metall. Mater. Trans. A 33, 1659-1667 (2002)

22. I. Tamura, Y. Tomota, H. Ozawa, in Proceedings of 3rd International Conference on Strength of Metals and Alloys (Cambridge, England, 1973), p. 611

23. G.D. Bokuchava, Y.E. Gorshkova, V. Papushkin, S. Guk, R. Kawalla, Investigation of plastically deformed TRIP-composites by neutron diffraction and small-angle neutron scattering methods. Surf. Invest. X-ray, Synchr. Neutr. Tech. 12(2), 227-232 (1995)

24. A. Yanina, S. Guk, W. Müller, R. Kawalla, C. Weigelt, Dynamic and static softening of sintered $\mathrm{MgO}-\mathrm{PSZ} / \mathrm{TRIP}$-matrix composites with up to 10 vol- $\% \mathrm{ZrO}_{2}$. Steel Res. Int. 82(9), 1158-1165 (2011)

25. A. Yanina, S. Guk, R. Kawalla, New TRIP-matrix-composite production, properties and softening behaviour during warm forming. Tagungsband der internationalen Konferenz "Neuere Entwicklungen in der Massivumformung". ISBN 978-3-88355-386-3, Fellbach/Stuttgart 17.05.-18.05.2011, pp. 271-281

26. M. Petrov, S. Guk, P. Petrov, J. Bast, Kraft- und Deformationscharakteristika beim Umformen eines Stahlblech-Verbundwerkstoffs. Lightweight Des. 5(5), 50-57 (2012)

27. S. Guk, D. Milisova, K. Pranke, Influence of deformation conditions on the microstructure and formability of sintered Mg-PSZ reinforced TRIP-matrix-composites. Key Eng. Mater. 684, 8696 (2016). Advanced materials and processes of metalworking. ISBN-13: 978-3-03835-522-9

28. S.S. Gorelik, Recrystallization in metals and alloys (MIR Publishers, Moscow, 1981)

29. K. Pranke, S. Guk, Material flow in Mg-PSZ particle reinforced TRIP-matrix-composites due to hot-rolling. Key Eng. Mater. 684, 97-103 (2016). Advanced materials and processes of metalworking. ISBN-13: 978-3-03835-522-9

30. Y. Prasad, S. Sasidhara, Hot working guide: a compendium of processing maps (ASM International, Materials Park, 1997) 
Open Access This chapter is licensed under the terms of the Creative Commons Attribution 4.0 International License (http://creativecommons.org/licenses/by/4.0/), which permits use, sharing, adaptation, distribution and reproduction in any medium or format, as long as you give appropriate credit to the original author(s) and the source, provide a link to the Creative Commons license and indicate if changes were made.

The images or other third party material in this chapter are included in the chapter's Creative Commons license, unless indicated otherwise in a credit line to the material. If material is not included in the chapter's Creative Commons license and your intended use is not permitted by statutory regulation or exceeds the permitted use, you will need to obtain permission directly from the copyright holder.

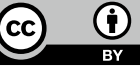

